\title{
Biosorption and adsorption of some heavy metals by Fusarium sp. F6c isolate as affected by gamma irradiation and agricultural wastes
}

\author{
Ola EA Al-Hagar ${ }^{\mathrm{a}}$, Reda A Bayoumi ${ }^{\mathrm{b}, \mathrm{c}, *}$, Osama A Abdel Aziz ${ }^{\mathrm{d}}$, Abeer M Mousa ${ }^{\mathrm{d}}$ \\ a Plant Research Department, Nuclear Research Center, Atomic Energy Authority, Egypt \\ b Botany and Microbiology Department, Faculty of Science, Al-Azhar University, Cairo, Egypt \\ c Biology Department, Khormah University College, Taif University, KSA \\ d Soil and Water Research Department, Nuclear Research Center, Atomic Energy Authority, Egypt \\ *Corresponding author, e-mail: reda.elbayoumi@yahoo.com, r.bayome@tu.edu.sa
}

Received 25 Nov 2018

Accepted 26 Dec 2019

\begin{abstract}
Various industries produce and discharge wastes containing different heavy metals into the environment. Biosorption as a biological method for removal of heavy metals from industrial and sewage wastewater has attracted the attention of researchers due to its unique properties compared to physical and chemical methods. The purpose of this study is to investigate the fungal biosorption of different heavy metals (lead ( $\mathrm{Pb}$ ), cadmium (Cd), copper (Cu), zinc ( $\mathrm{Zn}$ ), cobalt (Co), and chromium (Cr)) from wastewater. Through the current work, eight fungal isolates have been isolated from wastewater and investigated for their ability to grow in and uptake of different heavy metals. The most potent fungal isolate F6c was identified as Fusarium sp. based on morphological and physiological characterization. The strain $\mathrm{F} 6 \mathrm{c}$ has been investigated for its ability to grow at $100 \mathrm{ppm}$ of both $\mathrm{PbCl}_{2}$ and $\mathrm{CdCl}_{2}$. Evaluation of the effect of $\gamma$-irradiation on $\mathrm{Pb}$ and $\mathrm{Cd}$ uptake showed that the biosorption was improved at $1 \mathrm{kGy}$ but gradually suppressed at higher doses. Use of different agricultural wastes including rice bran, rice straw, wheat straw, maize wastes, and bagasse in combination with gamma irradiation improved both $\mathrm{PbCl}_{2}$ and $\mathrm{CdCl}_{2}$ uptake by $\mathrm{F} 6 \mathrm{c}$. Biosorption and adsorption techniques using the irradiation of Fusarium strain F6c could be a potential alternative to conventional methods in terms of availability of materials, cost-effectiveness as biosorbent for removal of high concentration metals from wastewater and industrial effluents.
\end{abstract}

KEYWORDS: adsorption, biosorption, Fusarium sp., heavy metals, mycoremediation, wastewater

\section{INTRODUCTION}

Heavy metals are emitted into the environment by sewage and waste materials from various resources such as metal plating, paint industry, metallurgy, released oil ingredients in the soil, combustion of fossil fuels, mining, ore washing, pesticides, colored materials, batteries, natural erosion of rocks and so on [1].

Although some metals are essential to the biological functions of plants and animals but at elevated levels, they interfere with metabolic reactions in systems of organisms. Toxic heavy metals such as lead $(\mathrm{Pb})$, cadmium (Cd), mercury $(\mathrm{Hg})$, chromium (Cr), zinc (Zn), nickel (Ni), and arsenic (As), which are not useful to plants, are capable of reducing plant growth due to the reduction of photosynthetic activities, plant mineral nutrition, and activity of essential enzymes [2]. Heavy metals could accu- mulate in agricultural soils and get into the food chain, thereby becoming a major threat to food security and health risks to living organisms [3]. The toxic effects of these compounds particularly on intervention in cellular enzymatic systems are able to impose their biological effects at the cellular level and cause severe detrimental effects on gastrointestinal, respiratory and nervous organs and tend to cause cell necrosis in the exposed organs [4]. Heavy metals are cytotoxic at low concentrations and could lead to cancers in humans [5]. Their existence also shows adverse effects on flora, fauna and leads to groundwater contamination through leaching. They reduce the performance and product quality in agriculture and are dangerous for public health and other living organisms [6].

Conventional and physical methods for metal removal are expensive and not effective in areas with low metal toxicity. It is important to note that 
the overall treatment cost of metal-contaminated water varies, depending on the process employed and the local conditions. In general, the technical applicability, plant simplicity and cost-effectiveness are the key factors in selecting the most suitable treatment for inorganic effluent. Bioremediation is an eco-friendly and efficient method of reclaiming environments contaminated with heavy metals by making use of the inherent biological mechanisms of microorganisms and plants to eradicate hazardous contaminants [7]. In bioremediation process, the microorganisms use contaminants as a source of nutrients and energy and convert them into soluble substances [8]. In this method, there is the possibility of removing one or more pollutants from environment, with a low cost, and remaining products have no detrimental effects on the ecosystem of contaminated sites [9].

Selection of biomass for using in bioremediation is very important; it should be abundant in the environment and adapted to environmental conditions [10]. The use of microorganisms such as algae, fungi, bacteria, and yeasts that can absorb heavy metals has been well considered in bioremediation of heavy metal polluted media [11]. In this way, microorganisms immobile metal ions by means of linking them with their cell walls [12]. Many contaminants have been remediated by fungi [13]. Some researchers achieved the removal of $\mathrm{Cd}$, Ni, and $\mathrm{Pb}$ using fungi with efficiency of $94.5 \%$ for $\mathrm{Cd}, 79.8 \%$ for $\mathrm{Ni}$, and $99.7 \%$ for $\mathrm{Pb}$ [14]. Others achieved 90\% removal efficiency of nickel with 0.1 milligrams of fungal biomass of Aspergillus niger [15]. Also in another study, $0.7 \mathrm{~g} / 1$ of fungal biomass of $A$. niger showed $84 \%$ removal of Cd [16]. Recent report showed that Fusarium solani KUSF204, a nonpathogenic saprophytic soil fungus, could tolerate different concentrations of a wide variety of heavy metals with the potential to produce phytohormones adequately. The Fusarium species is also peculiar in the sense that it produced an iron chelator called siderophore which negatively influences the microbial populations [17].

Therefore, this work aimed to isolate heavy metal resistance fungi and study the biosorption and adsorption process using the native and $\gamma$-irradiated fungus.

\section{MATERIALS AND METHODS}

\section{Samples}

Three wastewater samples were collected from different localities of drainage water in Bhnabai vil- lage, Zagazig, Egypt, in sterilized containers. These samples were brought to laboratory and kept at $4{ }^{\circ} \mathrm{C}$ for further processing.

\section{Preparation of agro-industrial wastes}

Agricultural wastes (wheat bran, rice bran, rice straw and maize wastes) were collected from different localities in Egypt. Sugar cane industry bagasse was also used. All these wastes were sun dried, ground and used in this work for bio-treatment of wastewater.

\section{Preparation of media}

Four media were prepared. Medium a contains the following $(\mathrm{g} / \mathrm{l})$ : yeast extract 10 , agar 20 , and wastewater $1 \mathrm{l}$; medium b (Czapek Dox medium) has the following composition $(\mathrm{g} / \mathrm{l})$ : sucrose 30 , sodium nitrate 3 , dipotassium phosphate 1 , magnesium sulphate 0.5 , potassium chloride 0.5 , ferrous sulphate 0.01 , and distilled water 11 [18] with the final $\mathrm{pH}$ adjusted to $7.3 \pm 0.2$; medium c (modified Czapek Dox medium) contains the previous composition as medium $b$ but using wastewater instead of distilled water; medium d contains the following composition $(\mathrm{g} / \mathrm{l})$ : industrial waste (bagasse) 50, yeast extract 20 , agar 20 , and wastewater 11 .

\section{Isolation and purification of heavy metal-resistant fungi}

Heavy metal-resistant fungi were isolated from wastewater samples using the previous media a, b, $\mathrm{c}$, and $\mathrm{d}$ by using spread plate method. The plates were incubated at $27^{\circ} \mathrm{C}$ for $4-7$ days. Plates were examined and different isolates were further purified by repeated single colony isolation. The fungal isolates were identified using cultural morphology and cellular techniques. The purification of heavy metal-resistant fungi was carried out according to the agar streak technique [19]. Cultural morphology to determine the colony color, shape, and texture was studied on PDA medium [20]. Eight fungal isolates, coded as F1a, F2b, F3b, F4b, F5c, F6c, F7c, and F8d according to isolated medium, have been screened, grown and preserved on modified Czapek Dox agar (medium c).

\section{Effect of heavy metals on growth of tested fungal isolates}

Eight tested fungi were grown and examined on Czapek Dox agar (medium b) amended with four heavy metals (zinc chloride, cadmium chloride, 
mercuric chloride, and lead chloride) at three concentrations of 50, 100, and $200 \mathrm{ppm}$. The capability of tested fungi to grow against heavy metals at different concentrations in solid condition was determined.

\section{Screening for heavy metal-resistant fungi}

Eight fungal isolates were grown on Czapek Dox broth medium with wastewater instead of distilled water (medium c) at $30^{\circ} \mathrm{C}$ for 7 days. The most promising heavy metal-resistant fungal isolates were subjected to screening for the ability in biosorption of metals such as $\mathrm{Pb}, \mathrm{Cd}, \mathrm{Cu}, \mathrm{Co}, \mathrm{Fe}$, and $\mathrm{Cr}$, then screened again for growth at high concentrations of $\mathrm{CdCl}_{2}$ and $\mathrm{PbCl}_{2}$. All the experiments were measured using inductively coupled plasma-optical emission spectrometer (ICP-OES optical emission, Teledyne-Leeman, USA) in The Central Laboratory for Elemental and Isotopic Analysis and XRF in Hot Laboratory, Nuclear Research Center, Atomic Energy Authority, Egypt.

\section{Identification of the most potent fungal isolate}

For macroscopic characterization of the mycelium, colony morphology, color, texture, shape, diameter, appearance, and pigmentation of the colony, etc., was observed and recorded. Microscopic identification was carried out with the slide culture technique, of which the fungi was cultured on thin PDA on glass slides (spore bearing fruiting body, spore size, growth rate hyphae, septation in mycelium, presence of specific reproductive structures, shape, and structure of conidia and presence of sterile mycelium were observed). Staining was performed using Lactophenol cotton blue (LPCB) stain. Then, the slide was observed under a light microscope. The spores, hyphae, and conidiophore arrangement were observed and recorded.

\section{Impact of different concentrations of cadmium chloride, lead chloride separately or combined on growth of Fusarium sp. F6c}

The most promising fungal isolate Fusarium sp. F6c was inoculated on Czapek Dox agar (medium b) amended with lead chloride and cadmium chloride separately or combined at different concentrations $(25,50,100,250,500$, and $1000 \mathrm{ppm})$. The strain was inoculated using disc on the middle of the plate, incubated for 7 days and then the growth zone was measured.
Effect of different doses of $\gamma$-radiation on growth, cadmium and lead uptake of Fusarium sp. F6c

Fusarium sp. F6c was inoculated on $100 \mathrm{ml}$ broth medium c in a shaking incubator at $30^{\circ} \mathrm{C}, \mathrm{pH} 6$ and $180 \mathrm{rpm}$ and subjected to $\gamma$-radiation at doses 0.5 , $1,2,3,5,10$, and $20 \mathrm{kGy}$ from Cobalt-60 gamma source with dose rate of $695.02 \mathrm{~Gy} / \mathrm{h}$ at the Nuclear Research Center, Atomic Energy Authority, Egypt, and then incubated for 7 days at $30^{\circ} \mathrm{C}$. The irradiated mixtures were tested for $\mathrm{Pb}$ and $\mathrm{Cd}$ uptake and compared with non-irradiated control.

\section{Effect of agro-industrial wastes alone or combined with irradiation on cadmium and lead uptake of Fusarium sp. F6}

Ten grams of agro-industrial wastes mentioned previously were added separately to $100 \mathrm{ml}$ wastewater, inoculated with the strain F6c irradiated with $1 \mathrm{kGy}$, and then incubated for 7 days. Estimation of cadmium and lead uptake was performed and compared with the non-irradiated control.

\section{Estimation of lead and cadmium in filtrate and mycelium of Fusarium sp. F6c}

Fungal biomass was removed after incubation period (36 h) from supplemented broth Czapek Dox (medium b) with or without cadmium and lead at concentration of $100 \mathrm{ppm}$. The cell-free supernatant was passed through filter paper (Whatman no. 42) and centrifuged at $1500 \mathrm{rpm}$ for $5 \mathrm{~min}$. The debris was discarded and the upper homogeneous layer without fungal particles was collected [21]. All experiments were conducted in three replicates. The supernatant filtrate was determined for lead and cadmium concentration using prodigy, high dispersion ICP, USA mode $b$. The fungal biomass was collected, washed, dried, and crushed to powder in a mortar and then used for adsorption estimation. Dry cell weight was gravimetrically estimated and separately determined for lead and cadmium uptake using X-ray fluorescence spectrometer model JSX3222 analyzer.

\section{Statistical analysis}

Independent variables are $\mathrm{pH}$ of the solution, different concentrations of heavy metals and various strains of Fusarium sp. The dependent variable is the removal efficiency of heavy metals in each of the solution. The obtained data were analyzed using PASW (SPSS 18) software. For testing of normality and distribution of data, the Kolmogorov-Smirnov 
test with 95\% confidence level was used. Twoway analysis of variance (ANOVA) was used for comparing of the means of obtained results [22].

\section{RESULTS}

\section{Isolation and screening of fungal isolates}

Eight isolates were able to grow in various concentrations (50-200 ppm) of different heavy metals as shown in Table 1 . All eight heavy metal-resistant fungal isolates exhibited the good growth at 50, 100, and $200 \mathrm{ppm}$ of zinc chloride, cadmium chloride and lead chloride but did not grow in mercuric chloride at $200 \mathrm{ppm}$.

For further screening, eight different morphological fungal isolates were obtained from the wastewater samples using media supplemented with different heavy metals (lead, cadmium, copper, cobalt, and chromium; zinc was omitted from this experiment due to its very low concentration in wastewater samples). F1a fungal isolate was grown on medium a; F2b, F3b, F4b, fungi isolates on medium b; F5c, F6c, F7c isolates on medium $c$, and F8d fungal isolate on medium d. The biosorption of different heavy metal uptake by the isolated fungal species was investigated (Table 2). The eight heavy metal-resistant fungi growing on experimental wastewater were capable of decreasing all heavy metals tested. The presence of high metal-absorption activity is an indicator of the most promising fungal isolate; the highest ability in heavy metal absorption especially was observed with $\mathrm{Pb}$, $\mathrm{Cd}$, and $\mathrm{Cr}$. We did not choose $\mathrm{Cr}$ for further study because initial concentration of this metal in wastewater samples was not so high compared to $\mathrm{Pb}$ and $\mathrm{Cd}$.

Isolates F6c and F7c exhibited heavy metal resistant and showed better growth on cadmium chloride and lead chloride and therefore were chosen for further study for absorption of heavy metals from wastewater. All fungal isolates were tolerant to all tested heavy metals at 50,100 ppm. However, only fungal isolate $\mathrm{F} 6 \mathrm{c}$ could tolerate all heavy metal concentrations at 50,100, and $200 \mathrm{ppm}$, exhibited the highest growth rate and consequently was selected for identification and further studies.

\section{Morphological and physiological identification of F6c}

The most promising fungal isolate $\mathrm{F} 6 \mathrm{c}$ was identified as Fusarium sp. according to the macroscopic and microscopic features (Fig. 1).

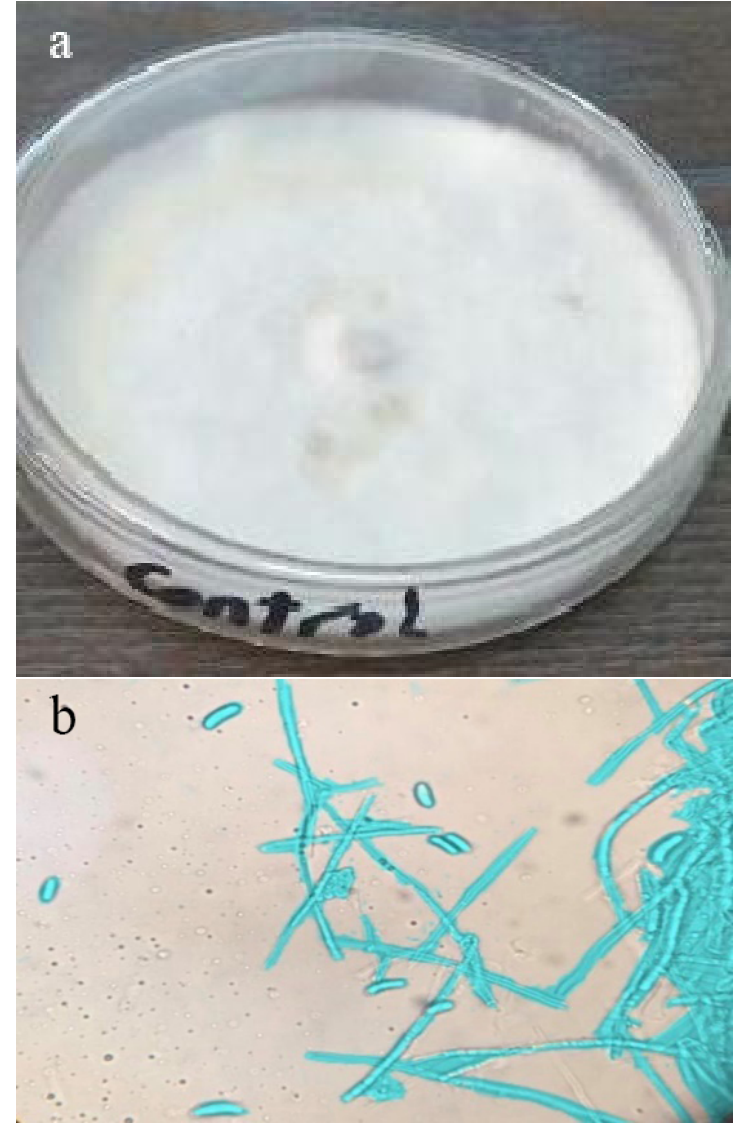

Fig. 1 Macroscopic image of (a) Fusarium sp. F6c; (b) Fusarium sp. F6c stained spores and mycelium under light microscope with magnification power of $10 \times 40$.

\section{Impact of different concentrations of cadmium chloride, lead chloride separately or combined on growth of Fusarium sp. F6c}

It is well known that exposure of water and sediment to heavy metals can produce considerable modification of their microbial populations, reducing their activity and their number. Fusarium sp. F6c exhibited decreased growth with increasing cadmium concentration from $25-1000$ ppm where the growth zone decreased from 8.5 to $2.5 \mathrm{~cm}$ (Fig. 2). While the growth of tested isolate was not affected by increasing lead concentration from 25-1000 ppm since stable growth at $9.0 \mathrm{~cm}$ was observed (Fig. S1). Maximum biosorption was recorded for cadmium chloride with lead chloride at low concentration of $25 \mathrm{ppm}$ and decreased gradually with the concentrations of $50,100,250$, and $500 \mathrm{ppm}$ while no growth was recorded at $1000 \mathrm{ppm}$ with cadmium chloride and mixture of cadmium and lead chloride (Fig. S2). Colony 
Table 1 Effect of different concentrations (ppm) of $\mathrm{ZnCl}_{2}, \mathrm{CdCl}_{2}, \mathrm{HgCl}_{2}$, and $\mathrm{Pb} \mathrm{Cl}_{2}$ on growth of tested fungi.

\begin{tabular}{|c|c|c|c|c|c|c|c|c|c|c|c|c|}
\hline \multirow{2}{*}{$\begin{array}{l}\text { Fungal } \\
\text { isolate }\end{array}$} & \multicolumn{3}{|c|}{$\mathrm{ZnCl}_{2}$} & \multicolumn{3}{|c|}{$\mathrm{CdCl}_{2}$} & \multicolumn{3}{|c|}{$\mathrm{HgCl}_{2}$} & \multicolumn{3}{|c|}{$\mathrm{PbCl}_{2}$} \\
\hline & 50 & 100 & 200 & 50 & 100 & 200 & 50 & 100 & 200 & 50 & 100 & 200 \\
\hline F1b & +++ & +++ & ++ & +++ & +++ & ++ & + & + & - & +++ & +++ & +++ \\
\hline $\mathrm{F} 2 \mathrm{~b}$ & +++ & +++ & ++ & ++ & ++ & ++ & + & + & - & +++ & +++ & +++ \\
\hline F3b & +++ & +++ & ++ & ++ & + & +++ & + & + & - & +++ & +++ & +++ \\
\hline $\mathrm{F} 4 \mathrm{~b}$ & +++ & +++ & ++ & ++ & + & +++ & + & + & - & +++ & ++ & ++ \\
\hline F5c & +++ & +++ & +++ & ++ & ++ & + & + & + & - & +++ & ++ & ++ \\
\hline F6c & +++ & +++ & +++ & +++ & +++ & +++ & ++ & ++ & + & +++ & +++ & +++ \\
\hline F7c & +++ & +++ & +++ & ++ & ++ & + & ++ & + & - & +++ & ++ & ++ \\
\hline F8d & +++ & +++ & ++ & ++ & ++ & + & + & + & - & +++ & ++ & ++ \\
\hline
\end{tabular}

- no growth, + weak, ++ good, and +++ very good.

Table 2 Heavy metal uptake (\%) from wastewater by fungal isolates.

\begin{tabular}{lccccc}
\hline Fungal isolate & $\mathrm{Pb}$ & $\mathrm{Cd}$ & $\mathrm{Cu}$ & $\mathrm{Co}$ & $\mathrm{Cr}$ \\
\hline F1b & 67.45 & 81.13 & 35.29 & 55.37 & 84.45 \\
F2b & 74.53 & 68.21 & 55.88 & 46.28 & 87.82 \\
F3b & 15.09 & 84.77 & 50.00 & 47.93 & 77.73 \\
F4b & 16.04 & 81.79 & 44.12 & 46.28 & 86.97 \\
F5c & 28.30 & 95.03 & 55.88 & 47.11 & 81.93 \\
F6c & 83.96 & 93.38 & 23.53 & 59.50 & 84.03 \\
F7c & 15.09 & 93.38 & 23.53 & 59.50 & 94.54 \\
F8d & 35.38 & 37.08 & 11.76 & 70.24 & 62.18 \\
\hline
\end{tabular}

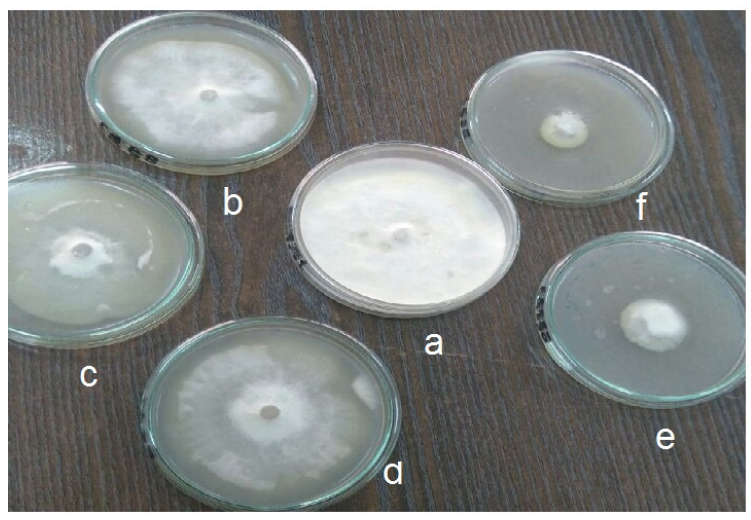

Fig. 2 Effect of different concentrations of cadmium chloride on growth of Fusarium sp. F6c: (a) control, (b) $25 \mathrm{ppm}$, (c) $50 \mathrm{ppm}$, (d) $100 \mathrm{ppm}$, (e) $250 \mathrm{ppm}$, (f) $500 \mathrm{ppm}$.

growth of Fusarium sp. F6c was inhibited at higher concentration of heavy metals while lower concentration of heavy metals either inhibited or had no effect on colony growth (Table 3). The data are expressed as diameter of growth zone in $\mathrm{cm} \pm \mathrm{SD}$ from three independent experiments.
Table 3 Effect of different concentrations of cadmium chloride, lead chloride and cadmium chloride with lead chloride metals on growth of Fusarium sp. F6c.

\begin{tabular}{cccc}
\hline $\begin{array}{c}\text { Heavy metal } \\
\text { (ppm) }\end{array}$ & $\begin{array}{c}\text { Cadmium } \\
\text { chloride }\end{array}$ & $\begin{array}{c}\text { Lead } \\
\text { chloride }\end{array}$ & $\begin{array}{c}\text { Cadmium \& } \\
\text { lead chloride }\end{array}$ \\
\hline 25 & $8.50 \pm 0.05$ & $9.0 \pm 0.01$ & $7.72 \pm 0.05$ \\
50 & $7.70 \pm 0.02$ & $9.0 \pm 0.01$ & $7.70 \pm 0.02$ \\
100 & $7.50 \pm 0.05$ & $9.0 \pm 0.01$ & $7.20 \pm 0.04$ \\
250 & $3.30 \pm 0.10$ & $9.0 \pm 0.02$ & $5.90 \pm 0.03$ \\
500 & $2.50 \pm 0.10$ & $9.0 \pm 0.01$ & $4.80 \pm 0.02$ \\
1000 & NG & $9.0 \pm 0.02$ & NG \\
\hline Control & - & $9.0 \pm 0.00$ & - \\
\hline
\end{tabular}

The data expressed as diameter of growth zone in petri dish $(\mathrm{cm} \pm \mathrm{SD})$ from three independent experiments; $\mathrm{NG}=$ no growth; Control = no heavy metal.

Table 4 Effect of various doses of $\gamma$-radiation on growth, $\mathrm{Cd}$ and $\mathrm{Pb}$ uptake by Fusarium sp. F6c.

\begin{tabular}{cccc}
\hline $\begin{array}{l}\text { Dose } \\
(\mathrm{kGy})\end{array}$ & $\begin{array}{c}\text { Dry weight } \\
(\mathrm{g} / 50 \mathrm{ml})\end{array}$ & $\begin{array}{c}\text { Cadmium } \\
\text { uptake }(\%)\end{array}$ & $\begin{array}{c}\text { Lead } \\
\text { uptake }(\%)\end{array}$ \\
\hline None & $0.44 \pm 0.001$ & 95.36 & 51.80 \\
0.5 & $0.33 \pm 0.001$ & 96.36 & 78.42 \\
1 & $0.42 \pm 0.001$ & 96.69 & 82.01 \\
2 & $0.53 \pm 0.001$ & 95.70 & 58.27 \\
3 & $0.46 \pm 0.001$ & 92.38 & 50.36 \\
5 & $0.44 \pm 0.001$ & 95.36 & 38.84 \\
10 & $0.06 \pm 0.001$ & 15.89 & 12.95 \\
20 & $0.02 \pm 0.001$ & 7.62 & 2.88 \\
\hline
\end{tabular}

\section{Effect of different doses of $\boldsymbol{\gamma}$-radiation on} growth, cadmium and lead uptake of F6c

The effect of different doses of gamma radiation on adsorption of heavy metals (Table 4) showed that the dose $1 \mathrm{kGy}$ especially improved lead adsorption compared to the non-irradiated control. On the other hand, the increase in the dose of radiation 
Table 5 Effect of agro-industrial wastes combined with $\gamma$ irradiation (1 kGy) on cadmium and lead uptake from wastewater by Fusarium sp. F6c.

\begin{tabular}{lcccc}
\hline \multirow{2}{*}{$\begin{array}{l}\text { Agro-industrial } \\
\text { waste }\end{array}$} & \multicolumn{2}{c}{ Cadmium uptake (\%) } & \multicolumn{2}{c}{ Lead uptake (\%) } \\
\cline { 2 - 5 } & Non-irr. & Irr. & Non-irr. & Irr. \\
\hline Rice bran & 99.97 & ND & 98.35 & ND \\
Rice straw & ND & ND & 97.27 & 94.17 \\
Wheat straw & 99.93 & ND & ND & 94.60 \\
Bagasse & 98.54 & 97.78 & 97.63 & ND \\
Maize waste & ND & 99.97 & 98.92 & 98.42 \\
None (no biomass) & - & 96.69 & - & 82.01 \\
\hline
\end{tabular}

Irr. = irradiated; $\mathrm{ND}=$ not determined.

Table 6 Estimation of lead and cadmium concentrations in the filtrate and mycelium of Fusarium sp. F6c.

\begin{tabular}{lccc}
\hline \multirow{2}{*}{ Heavy metal } & Dry weight & \multicolumn{2}{c}{ Concentration (ppm) } \\
\cline { 3 - 4 } & $(\mathrm{g} / 100 \mathrm{ml})$ & Filtrate & Mycelium \\
\hline $\mathrm{Pb}(100 \mathrm{ppm})$ & $0.45 \pm 0.03$ & $0.17 \pm 0.05$ & $99.8 \pm 0.01$ \\
$\mathrm{Cd}(100 \mathrm{ppm})$ & $0.36 \pm 0.01$ & $0.17 \pm 0.05$ & $99.8 \pm 0.01$ \\
Control & $0.43 \pm 0.03$ & 0.00 & 0.00 \\
\hline
\end{tabular}

Control $=$ no metal ion.

resulted in gradual decrease in heavy metal adsorption up to $20 \mathrm{kGy}$. Increase of $\gamma$-radiation over $20 \mathrm{kGy}$ inhibited the uptake of the organism.

\section{Effect of different agro-industrial wastes combined with irradiation on cadmium and lead uptake from wastewater by F6c}

Properties of adsorbent, $\mathrm{pH}$, concentration of adsorbent, and the presence of co-ions in solution affect the biosorption of metal ions from aqueous solutions. In this study, attempts were made to increase heavy metal uptake by Fusarium sp. F6c using different agro-industrial wastes with $1 \mathrm{kGy}$ of $\gamma$ radiation dose as the best gamma irradiation dose (Table 5). It was shown that exposing agroindustrial wastes to irradiation ( $1 \mathrm{kGy}$ ) gave nearly the same results as the non-exposing condition. This result implied that agro-industrial wastes could be used for biosorption of metal in replace of radiation.

\section{Estimation of lead and cadmium in filtrate and F6c mycelium}

Attempt was made to study the mechanism of Fusarium sp. F6c on the biosorption of two tested heavy metals (cadmium chloride and lead chloride). Measurement of the quantity of the two tested heavy metals in the filtrate (extracellular) using ICP and in mycelium (intracellular) using XRF was carried out. The results exhibited that fungus mycelium can harvest great amount [99.8 ppm] of $\mathrm{Cd}$ and $\mathrm{Pb}$, leaving the filtrate with slight amount of less than 0.2 ppm (Table 6).

\section{DISCUSSION}

Fungal enzymes degrade the heavy metals by incorporating them in their metabolic pathways and immobilizing them. Eight fungal isolates, namely F1a, F2b, F3b, F4b, F5c, F6c, F7c, and F8d, were grown in different concentrations (50-200 ppm) of zinc, cadmium, mercuric, and lead chloride (Table 1). All eight heavy metal-resistant fungal isolates exhibited the good growth at 50, 100, and 200 ppm of zinc chloride, cadmium chloride and lead chloride but did not grow in mercuric chloride at $200 \mathrm{ppm}$. Also, for further screening, all isolates growing on experimental wastewater were capable of decreasing five heavy metals (Table 2). In this respect, various metal resistant-fungi belonging to genera Aspergillus, Penicillium, Alternaria, Geotrichum, Fusarium, Rhizopus, Monilia, and Trichoderma were isolated from wastewater treated soil [23]. Other research groups had screened 36 microbes including fungi and yeast for their resistance to heavy metals [24]. We found eight filamentous fungal isolates that showed resistance to heavy metals including $\mathrm{Pb}, \mathrm{Cd}, \mathrm{Cu}, \mathrm{Co}$, and $\mathrm{Cr}$. However, many researchers demonstrated tolerance of heavy metals ( $\mathrm{Cr}$ and $\mathrm{Pb}$ ) by Fusarium spp. [25], while others [26] studied the level of tolerance of fungi against lead and selenium. Fusarium reached a maximum diameter in 4 days; the colonies grown on amended PDA showed inhibited growth on the 7th day of incubation. However, microorganisms isolated from contaminated sites were more tolerant than those from the control sites [27]. Microorganisms including fungi and bacteria have been reported to extract heavy metals from wastewater through bioaccumulation and biosorption. Attempts were made to isolate bacteria and fungi from sites contaminated with heavy metals for higher tolerance to be used in the removal of metals from wastewater.

In this work, the fungal isolate $\mathrm{F} 6 \mathrm{c}$, the most potent strain, was identified as Fusarium sp. by its physiological and morphological characters. Fusarium is a filamentous fungus found ubiquitously in soil and decaying plant materials, where it acts as a decomposer. F. solani isolates could leach and uptake $\mathrm{Cu}$ and $\mathrm{Zn}$ from insoluble $\mathrm{Cu}$ phosphate-containing and $\mathrm{Zn}$ phosphate-containing media [28]. Fusarium spp. was reported to show metal resistance to six heavy metals: $\mathrm{Cu}, \mathrm{Cr}, \mathrm{Pb}, \mathrm{Cd}$, $\mathrm{Sb}$, and $\mathrm{Ni}$ [29]. Another study [30] on F. molini- 
forme concluded that the fungus was a good indicator for consumption of contaminants, e.g. contaminated soils and hydrocarbon molecules. In addition to that, F. solani was able to bioaccumulate heavy metals in soil samples [28].

Data illustrated in Table 3 indicated the decrease of growth of Fusarium sp. F6c with increase in cadmium concentrations from 25-1000 ppm where the growth diameter significantly decreased. However, the growth of this fungus was not affected by increasing lead concentrations from 25-1000 ppm. Reduction in growth of fungi in the presence of higher concentrations of heavy metals may be due to an increase in length of the initial (lag) phase. The fungal isolate might respond to these heavy metals by several processes, including transport across the cell membrane, biosorption to the cell walls and entrapment in extracellular capsules, precipitation, complexation and oxidation-reduction reactions [31]. This proves the possible utilization of selected fungal isolate as a nature's original recyclers that not only functioned under a broad spectrum of conditions like $\mathrm{pH}$, temperature, etc., but also found economically feasible due to the cheap raw supplies that can be utilized as biosorbents [32].

Effect of different doses of radiation on adsorption of heavy metals (Table 4) showed that the dose $1 \mathrm{kGy}$ improved $\mathrm{Cd}$ and $\mathrm{Pb}$ adsorption compared to the non-irradiated control. On the other hand, the increase in the dose of radiation resulted in gradual decrease in $\mathrm{Cd}$ and $\mathrm{Pb}$ adsorption up to $20 \mathrm{kGy}$. Increase of $\gamma$-radiation over $20 \mathrm{kGy}$ inhibited the organism. In this regard, gamma rays are short wave high-energy electromagnetic radiations capable of ionizing other atoms [33]. Gamma radiation has also been reported to increase the level of activity of many enzymes at low levels [34]. At higher levels of $\gamma$-radiation, the enzyme(s) responsible for reduction of heavy metal is disrupted and subsequently, heavy metal adsorption is reduced. On the other hand, some studies reported that $\gamma$-radiation is able to produce amino acids by breaking down of proteins [35]. High level of radiation causes DNA damage.

The results in Table 5 clarified that all different agro-industrial wastes incubated with the strain F6c could be used for bio-absorption of cadmium and lead metal ions (gave nearly the same result) with or without $1 \mathrm{kGy} \gamma$ irradiation dose. Using agroindustrial waste or biomass instead of radiation is suggested. Fungal mycelium could harvest great amount [99.8 ppm] of heavy metals (Table 6). The differences between the sampled sites regarding their richness on microbial isolates appear to be closely linked to the degree of heavy metal pollution. Generally, pollution of soil and water by heavy metals may lead to a decrease in microbial diversity. The sources of pollutant as well as long period of exposure are also the important factors regulating the stress and fungal adaptation [36].

In the present study, the Fusarium sp. F6c showed tolerance to investigated heavy metals. The process of biosorption is dependent on factors including fungal species, biosorbent size, metal concentration and ionic composition. Fungi constitute a high proportion of the microbial biomass in water and soil. Being widespread in soil, their large surface to volume ratio and high metabolic activity, fungi can contribute significantly to heavy metal dynamics in soil [37]. Fungi have been proven more efficient and economical for removal of toxic metals from dilute aqueous solution because of their filamentous morphology and high percentage of cell walls [38].

\section{CONCLUSION}

Many aquatic environments face metal concentrations that exceed water criteria designed to protect the environment, animals and humans. Every essential element is toxic if taken in excess and there is a safe window for essential dose between deficiency and toxicity. Biological absorption is an effective technology for the optimal removal of heavy metals. In this process, adsorption and desorption rates are very high. Simplicity of the operation makes this technique the good way to remove toxic materials from the environment. Fusarium sp. F6c is the terricolous fungi that showed the absorption ability of heavy metals from aqueous solutions. One of the advantages of absorption by fungi is high-speed absorption. Based on the results of this work, it could be more economical and more preferable to use biosorption method to remove heavy metals in wastewater than other conventional methods as it minimizes chemical and biological sludges with the possibility of metal and biosorbent recovery.

\section{Appendix A. Supplementary data}

Supplementary data associated with this article can be found at http://dx.doi.org/10.2306/ scienceasia1513-1874.2020.008.

\section{REFERENCES}

1. Vadkertiova R, Slavikova E (2006) Metal tolerance of yeasts isolated from water, soil and plant environments. J Basic Microbiol 46, 145-152. 
2. Nemation MA, Kazemeini F (2013) Accumulation of $\mathrm{Pb}, \mathrm{Zn}, \mathrm{C}$ and $\mathrm{Fe}$ in plants and hyperaccumulator choice in Galali iron mine area Iran. Int J Agric Crop Sci 5, 426-432.

3. Tak HI, Ahmad F, Babalola OO (2013) Advances in the application of plant growth-promoting rhizobacteria in phytoremediation of heavy metals. In: Whitacre DM (ed) Reviews of Environmental Contamination and Toxicology 223, Springer Science and Business Media, New York, pp 33-52.

4. Saberi M, Tavali A, Jafari M, Heidari M (2010) The effect of different levels of heavy metals on seed germination and seedling growth of Atriplex lentiformis. $J$ Range Manage 4, 112-120.

5. Dixit R, Wasiullah, Malaviya D, Pandiyan K, Singh UB, Sahu A, Shukla R, Singh BP, et al (2015) Bioremediation of heavy metals from soil and aquatic environment: An overview of principles and criteria of fundamental processes. Sustainability 7, 2189-2212.

6. Khosravi F, Savaghebi GH, Farah Bakhsh H (2009) Effect of potassium chloride on Cd uptake by colza in a polluted soil. Water Soil J 23, 28-35.

7. Ojuederie OB, Babalola OO (2017) Microbial and plant-assisted bioremediation of heavy metal polluted environments. Int $J$ Environ Res Public Health 14, ID 1504.

8. Kumar R, Bishnoi NR, Bishnoi GK (2008) Biosorption of chromium (VI) from aqueous solution and electroplating wastewater using fungal biomass. Chem Eng J 135, 202-208.

9. Mohsenzadeh F, Chehregani Rad A, Akbari M (2012) Evaluation of oil removal efficiency and enzymatic activity in some fungal strains for bioremediation of petroleum-polluted soils. Iran J Environ Health Sci Eng 9, 26-34.

10. Kumar RR, Lee JT, Cho JY (2012) Toxic cadmium ions removal by isolated fungal strain from e-waste recycling facility. $J$ Environ Appl Biores 1, 1-4.

11. Pradhan S, Singh S, Rai LC (2007) Characterization of various functional groups present in the capsule of Microcystis and study of their role in biosorption of Fe, Ni and Cr. Bioresour Technol 98, 595-601.

12. Vankar PS, Bajpai D (2008) Phytoremediation of Chrome-VI of tannery effluent by Trichoderma species. Desalination 222, 255-262.

13. Dugal S, Gangawane M (2012) Metal tolerance and potential of Penicillium species for use in mycoremediation. J Chem Pharm Res 4, 2362-2366.

14. Farzin H (2010) The study of bacteria, fungi and other microorganisms for the treatment of heavy metals and petroleum hydrocarbons from water and environment. In: Proc 3rd Nat Conf Environ Health, Kerman, Iran.

15. Amini M, Younesi H, Ghorbani F, Daneshi A (2008) Biological removal of heavy metals $\mathrm{Cd}, \mathrm{Ni}$ and $\mathrm{Pb}$ in ternary mixtures of plant wastewater using fungal biomass Aspergillus niger. In: Proc 2nd Conf Exhibit
Environ, Tehran, Iran, ID CEE02_36. [in Persian]

16. Congeevaram S, Dhanarani S, Park J, Dexilin M, Thamaraiselvi K (2007) Biosorption of chromium and nickel by heavy metal resistant fungal and bacterial isolates. J Hazard Mater 146, 270-277.

17. Roushan I, Bejoysekhar D (2017) Characterization of Fusarium solani kusf204 as a potential metal tolerant plant growth promoting fungus. IJPBS 7, 151-161.

18. Eaton AD, Clesceri LS, Greenberg AE, Franson MAH (1998) Standard Methods for the Examination of Water and Waste Water, APHA, Washington, DC.

19. Collins CH, Lyne PM (1985) Microbiological Methods, 5 th edn, Butter Worth, London.

20. Gilman JC (1957) A Manual of Soil Fungi, Oxford and IBH Publishing, New Delhi.

21. Chergui A, Bakhti MZ, Chahboub A, Haddoum S, Selatnia A, Junter GA (2007) Simultaneous biosorption of $\mathrm{Cu}^{2+}, \mathrm{Zn}^{2+}$ and $\mathrm{Cr}^{6+}$ from aqueous solution by Streptomyces rimosus biomass. Desalination 206, 179-184.

22. Mohsenzadeh F, Nasseri S, Mesdaghinia A, Nabizadeh R, Chehregani A, Zafari D (2009) Identification of petroleum resistant plants and rhizospheral fungi for phytoremediation of petroleum contaminated soils. J Jpn Petrol Inst 52, 198-204.

23. Zafar S, Aqil F, Ahmad I (2007) Metal tolerance and biosorption potential of filamentous fungi isolated from metal contaminated agriculture soil. Bioresour Technol 98, 2557-2561.

24. Ezzouhri L, Castro E, Moya M, Espinola F, Lairini $\mathrm{K}$ (2009) Heavy metal tolerance of filamentous fungi isolated from polluted sites in Tangier, Morocco. Afr $J$ Microbiol Res 3, 35-48.

25. Iram $S$, Kousar P, Jawaria U, Kinat $N$, Noreen $A$, Sana A, Iftikhar A (2012) Heavy metal tolerance of filamentous fungal strains isolated from soil irrigated with industrial wastewater. Biologija 58, 107-116.

26. Jacob JM, Bardhan SK, Raj Mohan B (2013) Selenium and lead tolerance in fungi isolated from sea water. IJIRSET 2, 2975-2982.

27. Malik A (2004) Metal bioremediation through growing cells. Environ Int 30, 261-278.

28. Hong JW, Park JY, Gadd GM (2010) Pyrene degradation and copper and zinc uptake by Fusarium solani and Hypocrealixii isolated from petrol station soil. $J$ Appl Microbiol 108, 2030-2040.

29. Kumari D, Pan X, Achal V, Zhang D, Al-Misned FA, Mortuza MG (2015) Multiple metal-resistant bacteria and fungi from acidic copper mine tailings of Xinjiang, China. Environ Earth Sci 74, 3113-3121.

30. Silva MB, Rondon JN (2013) Utilização de fungos de bambina biorremediação de solo contaminado. Rev Eletrônica Gest Educ Tecnol 10, 2175-2184.

31. Akhtar S, Muhammad MH, Ahmad R, Suthor V, Yasin M (2013) Metal tolerance potential of filamentous fungi isolated from soils irrigated with untreated 
municipal effluent. Soil Environ 32, 55-62.

32. Shazia I, Uzma, Sadia GR, Talat A (2013) Bioremediation of heavy metals using isolates of filamentous fungus Aspergillus fumigatus collected from polluted soil of Kasur, Pakistan. Int Res J Biol Sci 2, 66-73.

33. Fawzi EM, Hamdy HS (2011) Improvement of carboxymethyl cellulase production from Chaetomium cellulolyticum Nrrl 18756 by mutation and optimization of solid state fermentation. Bangladesh J Bot 40, 139-147.

34. Hameed A, Shah TM, Atta BM, Haq MA, Sayed H (2008) Gamma irradiation effects on seed germination and growth, protein content, peroxidase and protease activity, lipid peroxidation in desi and kabuli chickpea. Pak J Bot 40, 1033-1041.

35. Kiong LPA, Lai AG, Hussein S, Harun A (2008) Physi- ological responses of Orthosiphon stamineus plantles to gamma irradiation. Am-Euras J Sustain Agric 2, 135-149.

36. Edward RC, Anbazhagan K, Selvam GS (2006) Isolation and characterization of a metal resistant Pseudomonas aeruginosa strain. World J Microbiol Biotechnol 22, 577-585.

37. Sosak-Swiderska B (2010) The soil fungi communities and risk assessment of heavy metal contaminated soils management. Geophys Res Abstract 12, 143-157.

38. Verma P, Singh S, Verma RK (2016) Heavy metal biosorption by Fusarium strains isolated from iron ore mines overburden soil. Int $J$ Environ Sci Toxicol Res 4, 61-69. 


\section{Appendix A. Supplementary data}

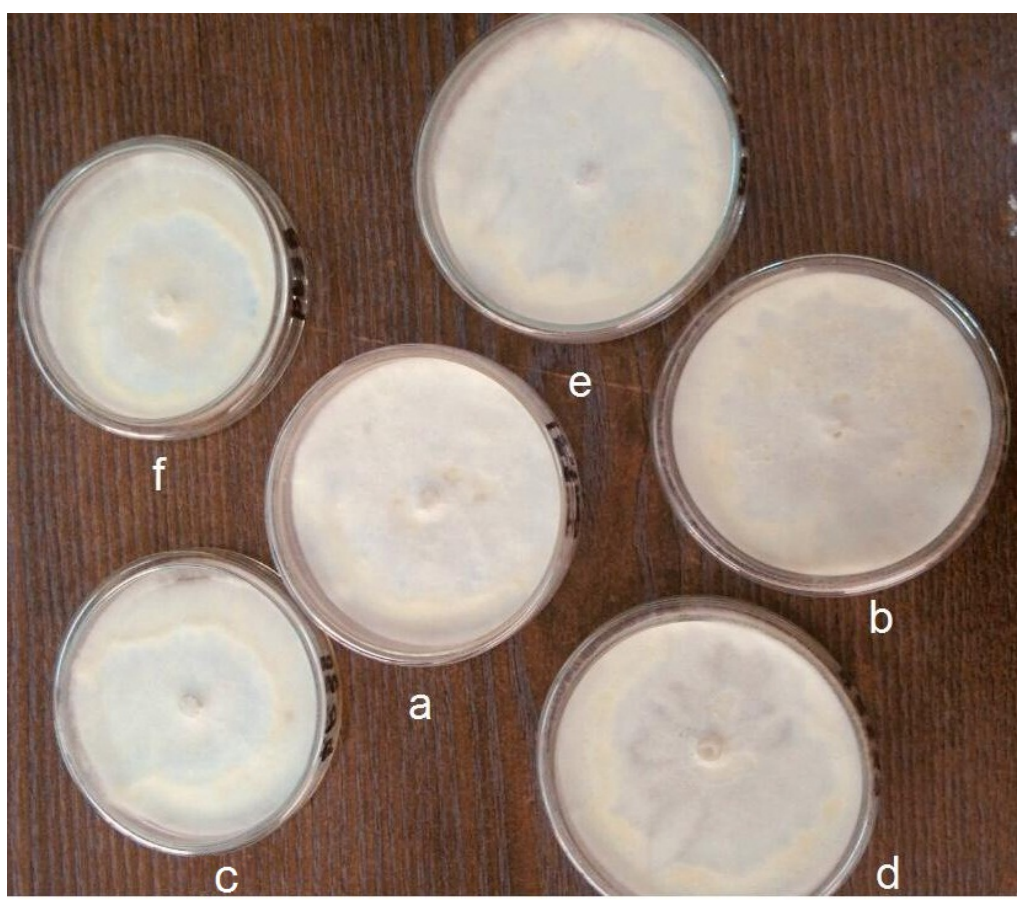

Fig. S1 Effect of different concentrations of lead chloride on growth of Fusarium sp. F6c.

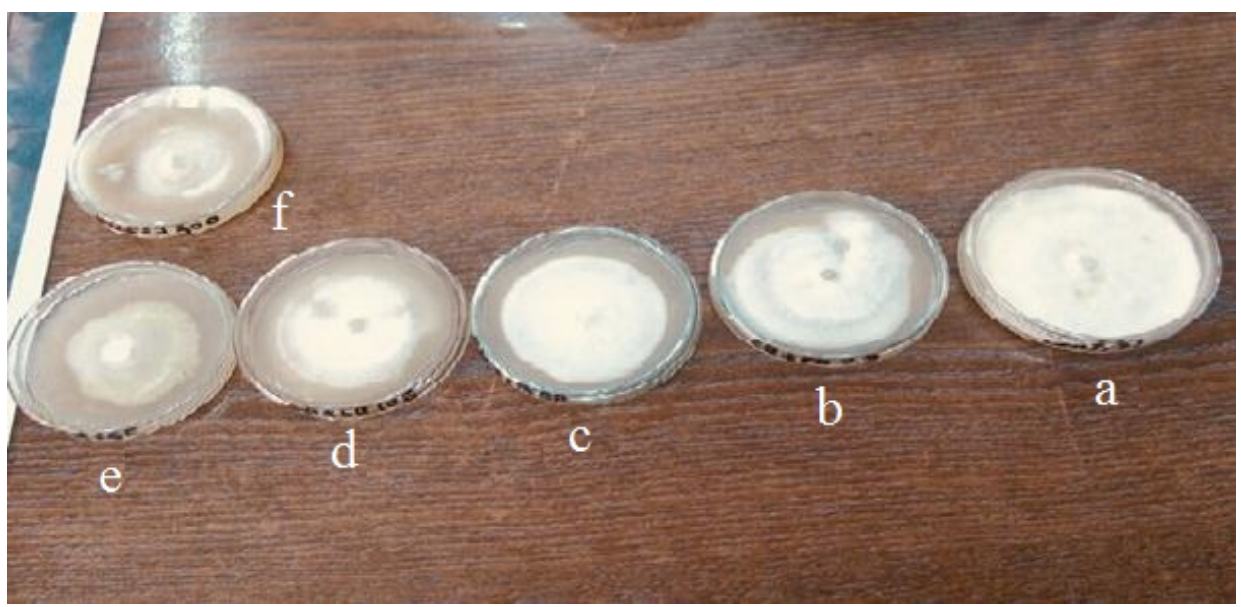

Fig. S2 Effect of different concentrations of cadmium chloride combined with lead chloride on growth of Fusarium sp. F6c. 